\title{
Cell-free biosynthesis of $\omega$-hydroxy acids boosted by a synergistic combination of alcohol dehydrogenases
}

\author{
Susana Velasco-Lozano[a], Javier Santiago-Arcos[a], Maria Grazia Rubanu[a] and Fernando López- \\ Gallego ${ }^{[a, b] *}$
}

\author{
[a]Heterogeneous biocatalysis group, CIC biomaGUNE, Edificio Empresarial "C", Paseo de Miramón 182, 20009, Donostia, Spain. \\ [b] IKERBASQUE, Basque Foundation for Science, Bilbao (Spain) \\ ${ }^{*}$ Corresponding author. (F. López-Gallego) \\ Tel: +34 943003500 Ext 309, Fax: +34 943003501 \\ E-mail addresses: (F. López-Gallego) flopez@cicbiomagune.es \\ Supporting information for this article is given via a link at the end of the document.
}

\begin{abstract}
The activity orchestration of an unprecedented cell-free enzyme system with self-sufficient cofactor recycling enables the step-wise transformation of aliphatic diols into $\omega$-hydroxy acids at the expense of molecular oxygen as electron acceptor. The efficiency of the biosynthetic route was maximized when two compatible alcohol dehydrogenases were selected as specialist biocatalysts for each one of the oxidative steps required for the oxidative lactonization of diols. The cell-free system reached up to $100 \%$ conversion using $100 \mathrm{mM}$ of linear C5 diols, and performed the dessymetrization of prochiral branched diols into the corresponding $\omega$-hydroxy acids with an exquisite enantioselectivity (ee > 99\%). Green metrics demostrate a superior sustanability of this system compared to traditional metal catalysts and even to whole cells for the synthesis of 5-hydroxy petanoic acid. Finally, the cell-free system was assembled into a consortium of heterogeneous biocatalysts that allowed the enzyme reutilization. This cascade illustrates the potential of systems biocatalysis to access new heterofunctional molecules such as $\omega$ hydroxy acids.
\end{abstract}

\section{Introduction}

Manufacturing of $\omega$-hydroxy acids $(\omega-\mathrm{HA})$ exhibits a multitude of applications in chemical industry since they are used in the production of several commodities such as resins, plasticizers and lubricants. ${ }^{[1]}$ In the polymer industry, $\omega$-HAs show high potential as precursors for the next generation of biodegradable polyesters (i.e. biomedical applications). ${ }^{[2]}$ Long-chain $\omega$-HA are naturally occurring in cutin, a biopolyester that forms the plant cuticule. ${ }^{[3]}$ However, medium and short chain $\omega$-HA are mainly accessed through chemical synthetic methods that require protected substrates and expensive metal catalysts, limiting the process sustainability. ${ }^{[4]}$ In a more environmentally friendly approach, engineered microbes have been exploited to efficiently synthesize medium and short chain $\omega$-HA from renewable organic acids $^{[5]}$ and 5-hydroxymethylfurfural, [6] but also from fossil cycloalkanes ${ }^{[7]}$ and cyclohexanol. ${ }^{[8]}$ As alternative, 4-enzyme cellfree system has been assembled in solution to sequentially perform hydratation, oxidative Baeyer-Villiger esterification and hydrolysis steps that synthesize medium-chain $\omega$-HAs from unsaturated fatty acids. ${ }^{[9]}$ Unfortunately, the atom economy of this process is rather low as the starting long chain fatty acids is chopped down yielding a mixture of the corresponding medium chain $\omega$-HAs and monocarboxylic acids. Besides the lack of product purity ( $\omega$-HAs are mixed with monocarboxylic acids), such route cannot yield short-chain $\omega$-HAs ( $\leq 6$ carbons). Hence, the cell-free biosynthesis of short-chain $\omega$-HAs is unmet need despite the large enzyme toolbox nowadays existing. Inspired by the microbial non-phosphorylative oxidative pathway for pentose degradation, ${ }^{[10]}$ we envision an elegant yet unexplored route to directly access short-chain $\omega$-HAs through the concurrent oxidative lactonization and lactone hydrolysis catalyzed by oxidoreductases and lactonases, ${ }^{[11]}$ respectively. Such route would be endorsed by the success of the already proven biosynthesis of lactones from short-chain cyclic ketones ${ }^{[9,12]}$ and cycloalkanes $^{[8]}$ using NADPH-dependent cell-free multi-enzyme systems based on monooxygenases and dehydrogenases. The industrial implementation of these cell-free systems may be cumbersome due to the low stability and high cost of the phosphorylated nicotinamide cofactor NADPH. As alternative, renewable diols ${ }^{[13]}$ can also be converted into lactones through a two-step oxidative lactonization catalyzed by NADH-dependent alcohol dehydrogenases incorporating different enzymatic cofactor regeneration approaches ${ }^{[14]}$ and smart co-substrates. ${ }^{[15]}$ In this scheme, the same alcohol dehydrogenase selectively oxidizes one primary alcohol of the starting diol to yield the corresponding hydroxyaldehyde that forms an equilibrium with its corresponding lactol, which is subsequently oxidized by the same enzyme to form the final lactone, shifting the aldehyde/lactol equilibrium towards the lactol formation. TEMPO-assisted laccase reaction has also proven useful for this biotransformation. ${ }^{[16]}$ Recently, a similar double consecutive oxidation of aliphatic and aromatic diols elegantly yields $\omega-\mathrm{HA}$ in a cofactor-free system using an engineered alcohol oxidase from Phanerochaete chrysosporium (PcAOX $\left.{ }^{\star}\right) .{ }^{[17]}$ The main limitation of these three last systems is the use of the same enzyme to catalyze the two oxidation steps, being the lactol oxidation the rate-limiting one.

In this study we aim at designing and applying an unprecedented cell-free five-enzyme system for the biosynthesis of short-chain $\omega$-HAs from bio-based 1,w-diols. ${ }^{[18]}$ Here, two alcohol dehydrogenases (ADH) selectively and concurrently catalyze the diol and lactol oxidations to form the lactone, which is finally hydrolyzed by a lactonase (LAC) to yield the target $\omega-\mathrm{HA}$. To balance the cofactor pool demanded by the ADHs, we integrate a $\mathrm{NADH}$ oxidase (NOX) that regenerates $\mathrm{NAD}^{+}$yielding $\mathrm{H}_{2} \mathrm{O}_{2}$ as byproduct that is in situ eliminated by incorporating a catalase (CAT) (Scheme 1). 


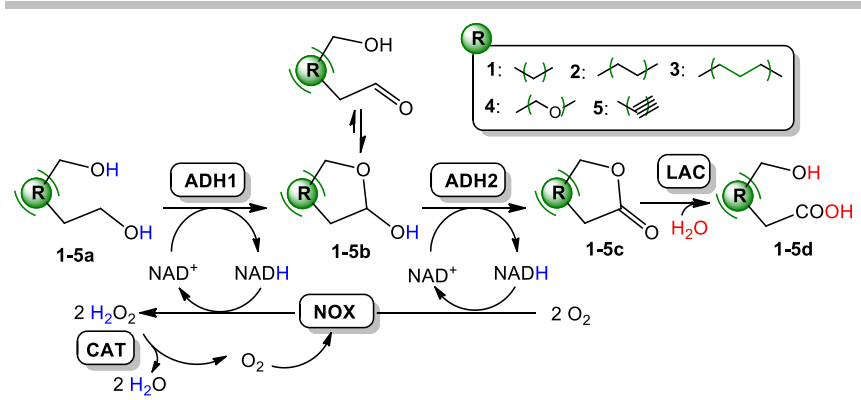

Scheme 1. One-pot cell-free biocatalytic cascade synthesis of short-chain $\omega$ HA from diols.

\section{Results and Discussion}

\section{Cascade optimization}

In our first attempt, we performed the synthesis of 5-hydroxy pentanoic acid (2d) combining a commercial crude extract of ADH from horse liver (HLADH) (Supporting Information, Fig. S1) as sole dehydrogenase and the pure His-tagged lactonase from Sulfolobus islandicus (SiLAC) (Supporting Information, Fig. S2), together with an excess of the widely used $\mathrm{NAD}^{+}$recycling system formed by a pure thermostable NOX from Thermus thermophilus (TtNOX) and the catalase from bovine liver (BICAT) (commercial crude extract). ${ }^{[19]}$ We did not select the a water-forming NOX, since our previous studies show that the TtNOX outperforms the former one exhibiting higher operational stability[19b, 20] Furthermore, the tandem TtNOX BICAT stoichiometrically demands the half of oxigen for the $\mathrm{NAD}^{+}$recylcling than the waterforming oxidases, a fact that positively impacts on the atom economy of the process. Figure $1 \mathrm{~A}$ shows the reaction time course of the four-enzyme system using an enzyme activity ratio of 2:1:10:100 (HLADH : SiLAC : TtNOX : BICAT), where the lactol intermediate $(\mathbf{2 b})$ is accumulated during the first 5 hours, and the $\omega$-HA yield $(\mathbf{2 d})$ reached $60 \%$ after $24 \mathrm{~h}$. On the contrary, the lactone intermediate is negligibly accumulated as SiLAC hydrolyzes the lactone $\mathbf{2 c} 214$ times more efficiently than the HLADH oxidizes the lactol $\mathbf{2 b}$ (Supporting Information, Table S1). Evaluating other lactonases, we found that SiLAC reaches 1.5 times higher and similar yield than the lactonases from Rhodococcus erythropolis (ReLAC) and from Homo sapiens

A

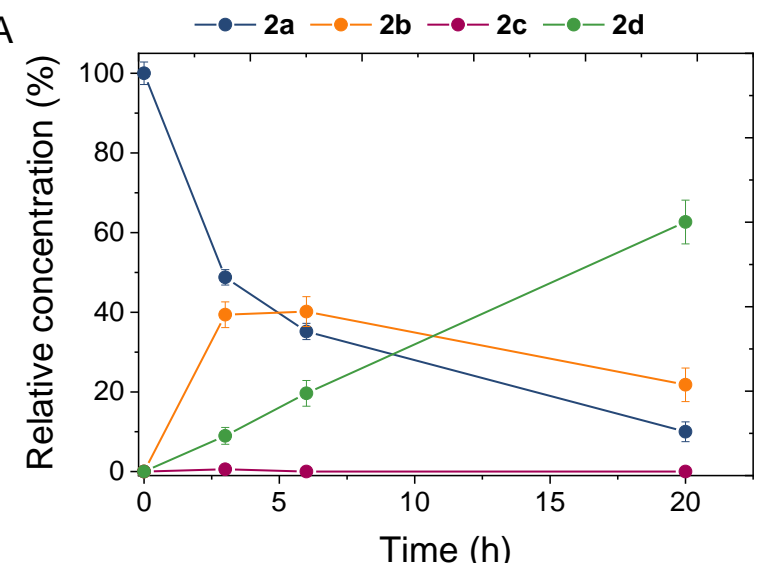

(RePON1), respectively, in agreement with their specific activities (Supporting Information, Fig. S3 and Table S2).

In order to minimize the lactol accumulation, we incorporated an additional dehydrogenase that outperforms HLADH for the diol conversion to dominate the first oxidation step, thus HLADH can focus on the second and limiting lactol oxidation step. We found that the ADH from Bacillus stearothermophilus (BsADH) performed the first step 12-fold faster ( $\mathrm{k}_{\mathrm{cat}}=30.2 \mathrm{~s}^{-1}$ towards the diol (2a) than HLADH (Supporting information, Table S1), and poorly oxidized the lactol (2b) (Supporting information, Figure S4). Moreover, BsADH and HLADH showed similar $\mathrm{K}_{\mathrm{M}}$ (0.6-0.9 mM) values towards $\mathrm{NAD}^{+}$suggesting that both enzymes will work at their maximal rate under the sub-stoichiometric concentration of cofactor typically used in bio-redox transformations. When different activity ratios HLADH:BsADH were assayed, we identified such ratio as one of the key parameters to maximize $\omega$ $\mathrm{HA}$ yield (Fig. 1B). In fact, when the system was conducted solely with $\mathrm{BsADH}$, the $\omega$-HA yield was extremely low (13\%) despite the high conversion of the diol $(86 \%)$, which gave rise to a large accumulation of lactol (70\%) (Supporting Information, Fig. S5). This insight entails BsADH as the specialist enzyme for the first oxidation within this enzyme cascade. A similar product distribution was found using the immobilized version of this enzyme towards the same substrate and under similar reaction conditions. ${ }^{[20]}$ Likewise, when the system was performed by the $\mathrm{HLADH}$ as the unique ADH (even at different amounts, 40 (ratio $0: 1$ ) or $120 \mathrm{mU}($ ratio $0: 3)$ ), the transformation only reached $60 \%$ of $\omega$-HA yield, similar to the yield achieved with the combination of the two ADHs using a activity ratio 4:1. Pleasently, the activity ratio 4:3 (BsADH:HLADH) achieved the highest $\omega$-HA yield (97\%) with a quantitative conversion of the diol $(\mathbf{2 a})$, attaining a total turnover number for $\mathrm{NAD}^{+}\left(\mathrm{TTN}_{\mathrm{NAD+}}\right)$ of 38.8 (close to the theoretical maximum of 40) (Fig. 1B) (Supporting Information, Figure S5). The resulting $\omega-\mathrm{HA}(\mathbf{2 d})$ was characterized by GC$\mathrm{MS}$ and ${ }^{1} \mathrm{H}$ NMR (Supporting Information, Figs. S6 and S7). Higher BsADH:HLADH activity ratios drove to lower $\omega$-HA yields (Fig. 1B). The synergistic use and the activity orchestration of these two ADHs enhance the overall reaction yield due to the negligible accumulation of the lactol, demonstrating that BsADH mainly oxidizes the diol, relegating HLADH from its task in the first oxidation. This fact allows HLADH to be focused exclusively on the lactol oxidation avoiding its accumulation in the reaction media

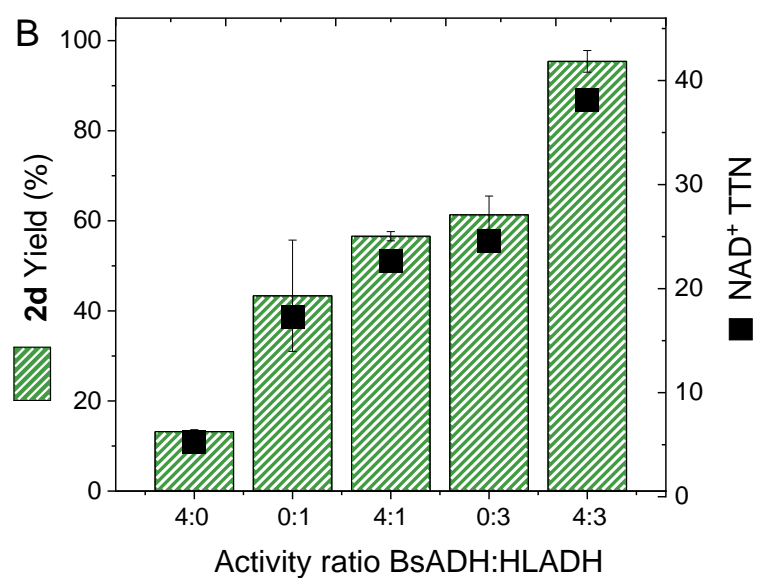

Figure 1. Multi-enzyme synthesis of $\omega$-hydroxy acids from diols. A) Reaction course consisting in $0.5 \mathrm{~mL}$ of $20 \mathrm{mM} 2 \mathrm{a}, 1 \mathrm{mM} \mathrm{NAD}$, $0.15 \mathrm{mM} F A D^{+}$in $100 \mathrm{mM}$ sodium phosphate buffer $\mathrm{pH} 8$ at $30{ }^{\circ} \mathrm{C}$ and $250 \mathrm{rpm}$, containing $\mathrm{HLADH}(40 \mathrm{mU})$, TtNOX ( $\left.200 \mathrm{mU}\right)$, BICAT (2 U) and SiLAC (20 mU). $100 \%$ of relative concentration corresponds to $20 \mathrm{mM}$. B) Biosynthesis optimization. All reactions consisted in $0.5 \mathrm{~mL}$ of $20 \mathrm{mM} 2 \mathrm{a}, 1 \mathrm{mM} \mathrm{NAD}+0.15 \mathrm{mM}$ FAD ${ }^{+}$in $100 \mathrm{mM}$ sodium phosphate buffer $\mathrm{pH} 8$ at $30 \stackrel{\circ}{\circ}$ and $250 \mathrm{rpm}$, containing one or two ADHs (BsADH:HLADH = 160:0 mU (4:0), 0:40 mU (0:1), 160:40 mU (4:1), 0:120 mU (0:3) or 160:120 $\mathrm{mU}(4: 3))$, TtNOX $(200 \mathrm{mU})$, BICAT $(2 \mathrm{U})$ and SiLAC $(20 \mathrm{mU})$, yield values correspond to $24 \mathrm{~h}$ of reaction. ADHs activity refer to the one exhibited with $2 \mathrm{a}$ as substrate. 
Table 1. Cascade multi-enzymatic synthesis of $\omega$-hydroxy acids from diols.

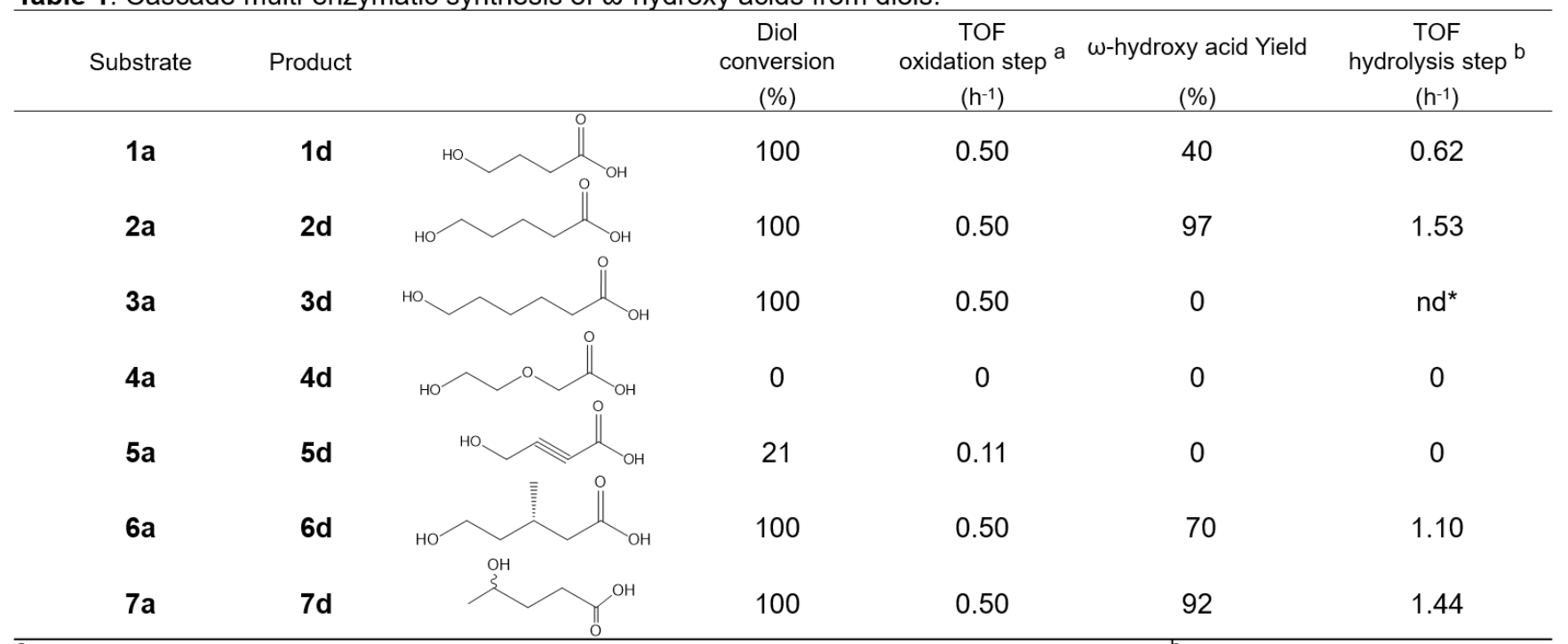

a TOFs of the oxidation step were calculated as the $\mu \mathrm{mol}$ of oxidized diol / $\mu$ mol of ADHs after 24 hours. ${ }^{b}$ TOFs of the hydrolysis step were calculated as the $\mu \mathrm{mol}$ of produced $\omega-\mathrm{HA} / \mu \mathrm{mol}$ of SiLAC after 24 hours. nd* The $\omega$-HA was overoxidized to form the corresponding aldehyde, therefore after 24 hours 3d was not detected. All reactions consisted in $0.5 \mathrm{~mL}$ of $20 \mathrm{mM}$ substrate, $1 \mathrm{mM} \mathrm{NAD}^{+}, 0.15 \mathrm{mM}$ FAD+ in $100 \mathrm{mM}$ sodium phosphate buffer $\mathrm{pH} 8$ at $30^{\circ} \mathrm{C}$ and $250 \mathrm{rpm}$, containing BsADH (160 mU), HLADH (120 mU), TtNOX (200 mU), BICAT (2 U) and SiLAC (20 mU).

and driving the cascade towards the target product. When we used the benchmark PcAOX* as the sole oxidative enzyme, we found that the cascade only reached $11 \%$ of $\omega$-HA yield $(\mathbf{2 d})$ under the same conditions as the optimized cascade using HLADH and BsADH (Supporting Information, Fig. S8). Moreover, when $\mathrm{PcAOX}{ }^{*}$ was combined with $\mathrm{BsADH}$, we observed a slight increase in the $\omega$-HA yield (17\%), but still 3.4 and 5.6 times lower than the ones achieved with the sole HLADH and the combination of $\mathrm{HLADH}$ and BsADH, respectively, as oxidative enzymes. The low performance of $\mathrm{PCAOX}^{*}$ as standalone oxidative enzyme relies on its low $k_{\text {cat }}$ towards the starting diol (2a) compared to BsADH (Supporting Information, Table S1). Regarding the oxidation of the lactol intermediate (2b), PcAOX ${ }^{*}$ accumulates 2 times more lactol than HLADH, (Supporting Information, Fig. S8), suggesting that neither does such oxidase outperform HLADH in the second oxidation step. Therefore, the combination of $\mathrm{PcAOX}^{*}$ and BsADH failed to reduce the lactol accumulation and reach high $\omega$-HA yields, concluding that these enzymes do not cooperatively work in this cascade as BsADH and HLADH do. In summary, we selected the pair BsADH-HLADH as the best candidate to catalyze the consecutive double oxidation of the diol and the SiLAC to achieve the most efficient lactone hydrolysis.

\section{Substrate scope and enanstioselectivity of the multi-enzyme system}

Once we identified the best enzymes and their optimal stoichiometry, we applied the five-enzyme system for the synthesis of chemically diverse short-chain $\omega$-HAs starting from a battery of seven linear and branched C4-C6 $\omega$-diols (1-7a). The multi-enzyme system successfully consumed more than $99 \%$ of all these diols but diethylene glycol (4a) and 1,4 butynediol 5a (Table 1). These results are aligned with the measured spectrophotometric activities of both ADHs towards these diols, where $\mathbf{4 a}$ and $\mathbf{5 a}$ were the least preferred ones (Supporting Information, Fig. S9). Besides, the cyclization of $\mathbf{5 b}$ is precluded due to the C2-C3 planar triple bond structure, supporting its unsuccessful lactonization and subsequent hydrolysis. Unlike
$\mathrm{PcAOX}^{*}$ which was engineered to accept polyols ${ }^{[17,21]}$, the active site of both BsADH and HLADH seems to hardly accommodate non-alkylic diols. Furthermore, BsADH exhibits higher specific activity than the HLADH towards all assessed diols but $6 \mathbf{a}$ (Supporting Information, Fig. S9), supporting the fact that BsADH relieves the workload of HLADH in the first oxidative step, letting the latter focus on the lactol oxidation. As general trend, the hydrolysis turnover frequency (TOF) was higher than the oxidation TOF (Table 1). Regarding the diol oxidation, similar trends were reported by Kara and co-workers, who described the preparation of lactones from diols (1a, 2a, 3a, 6a and 7a) employing HLADH coupled to a laccase mediator system. ${ }^{[14 a]}$ Despite 5 out the 7 assayed diols where completely consumed, the cell-free cascade only reached $\omega$-HA yields higher than $70 \%$ for $\mathbf{2 a}, \mathbf{6} \mathbf{a}$ and $\mathbf{7 a}$. Using the shortest diol (1a), the cell-free system reached $40 \%$ yield of $1 \mathrm{~d}$ which can be attributed to the high stability of 1c preventing its hydrolysis. Likewise, this system failed to synthesize the 6-hydroxy hexanoic acid (3d) despite its corresponding diol (3a) was quantitatively oxidized to the lactol. When we inspected deeper the product profile of $3 a$ after $24 \mathrm{~h}$, we identified 6-oxohexanoic acid (3e) as overoxidation product (Supporting Information, Fig. S10). This finding agrees to the high oxidative activity reported for BsADH towards long-chain $\omega-\mathrm{HA}$ to produce biobased polyamides where the formation of oxocarboxylic acids intermediates is desired. ${ }^{[22]}$ Unlike shorter $\omega$ $\mathrm{HA}$, the $6 \mathrm{C} \omega-\mathrm{HA}(\mathbf{3 d})$ reveals itself as substrate for the two dehydrogenases when it is accumulated (Supporting Information, Fig. S11). In fact, when we analyzed the reaction products at $2 \mathrm{~h}$, $4 \mathrm{~h}$ and $24 \mathrm{~h}$ by GC-MS, we could not detect $3 \mathrm{~d}$ even at the early reaction times, meanwhile all the aldehydes intermediates formed within this cascade could be detected (Supporting Information, Figs. S10 and S12).

Additionally, we tested the enantioselectivity of our cell-free biocatalytic cascade. To that aim, we challenged the multienzyme system with the prochiral 3-methyl-1,5-pentanediol (6a) to address its desymmetrization. After $24 \mathrm{~h}$ of reaction, $6 \mathrm{a}$ was $100 \%$ consumed, yielding $70 \%$ of $6 \mathbf{d}$ but accumulating the lactol intermediate and the overoxidation product 6-oxo-3-methyl 
pentanol (Supporting Information Figs. S13-S15). The enantiopurity of $\mathbf{6 d}$ was determined by chiral GC (Supporting Information, Fig. S16) where the presence of only one enantiomer (one chromatographic peak) points out that the cell-free cascade yields the $\omega-\mathrm{HA}$ with ee $>99 \%$. According to the previously reported exquisite $S$-enantiopreference (ee > 99) of HLADH during the oxidation of symmetric diols into 3 -substituted $\delta$ valerolactones ${ }^{[14 a]}[14 \mathrm{~b}]$, we conclude that our cell-free multienzyme system enantioselectivity synthesizes $S-6 d$. On the contrary, the multi-enzyme system showed null enantioselectivity for oxidizing the racemic mixture of 4-hydroxy pentanol 7a (rac7a). After $24 \mathrm{~h}$ of reaction, rac-7a was converted into its corresponding $\omega-\mathrm{HA}$, yielding $92 \%$ of rac-7d and suggesting that neither the ADHs nor the LAC are enantioselective for the oxidation and the hydrolysis step, respectively (Supporting Information, Figs. S17-S18). Again, this insight matches with the lack of enantioselectivity reported for HLADH towards the oxidation of rac-7a (82\%), which yields a racemic mixture of the corresponding lactone $(\mathrm{rac}-7 \mathrm{c}, \quad$ ee $=2 \%) .{ }^{[14 a]}$ The low enantiopreference of the multi-enzyme system towards rac-7a is also supported by the poor enantioselectivity found for SiLAC towards the hydrolysis of the racemic lactone rac-7c, $(e e<2 \%$, Supporting Information Fig. S19). A similar lack in enantioselectivity was observed for ReLAC (Supporting Information Fig. S20), which meant that the kinetic resolution of 7a was not possible using the dehydrogenases and lactonases herein tested. This means that the preparation of enantiopure $\mathbf{7 d}$ is forbidden using the cell-free biocatalytic cascade we described here.

Motivated by the excellent results we achieved with the transformation of diol $\mathbf{2 a}$, we scaled the substrate concentration up to $100 \mathrm{mM}$ using the optimized system stoichiometry. Under these conditions, a steady $\mathrm{pH}$ drop was observed during reaction course that slowed down the $\omega$-HA production after 4 hours (Fig. $2)$. The reduction of $\omega-\mathrm{HA}$ production rate relied on the inactivation of the cascade enzymes under operation conditions without $\mathrm{pH}$ control, where the ADHs and the CAT enzymes lost

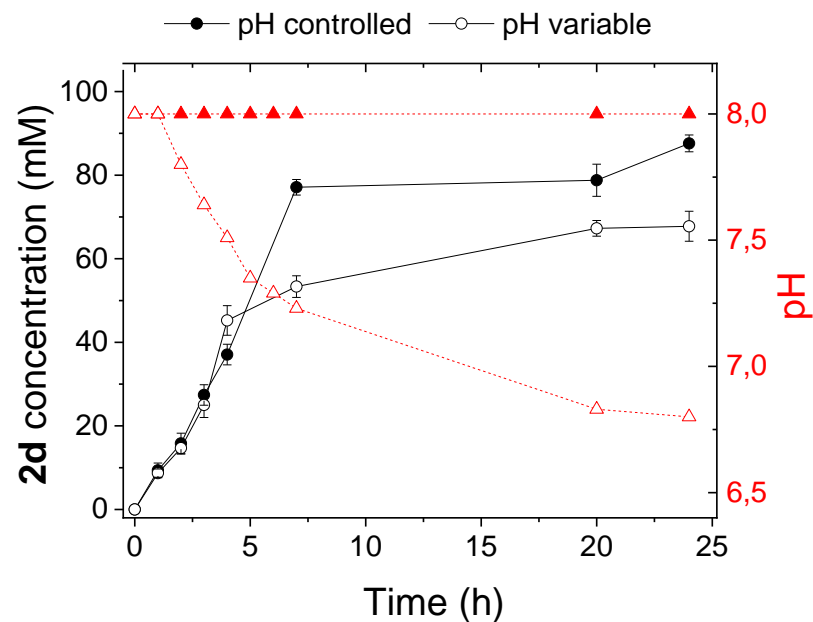

$60 \%$ of their initial activity after $24 \mathrm{~h}$ (Supporting Information, Fig. S21). To overcome the negative effect of the $\mathrm{pH}$ decreasing, we

Figure 2. Multi-enzyme synthesis of $\mathbf{2 d}$ from 2a $(100 \mathrm{mM})$. Effect of the $\mathrm{pH}$ on the initial $\omega$-HA production rate; reactions without $\mathrm{pH}$ control (empty symbols) and reactions with $\mathrm{pH}$ control (filled symbols). Triangles are reaction $\mathrm{pH}$. Circles: 2d concentration. All reactions consisted in $1.5 \mathrm{~mL}$ of $100 \mathrm{mM} \mathrm{2a}, 1 \mathrm{mM} \mathrm{NAD}^{+}$ $0.15 \mathrm{mM} \mathrm{FAD}^{+}$in $200 \mathrm{mM}$ sodium phosphate buffer $\mathrm{pH} 8$ at $30^{\circ} \mathrm{C}$ and $250 \mathrm{rpm}$, containing BsADH (0.8 U), HLADH (0.6 U), TtNOX $1 \mathrm{U}$, BICAT $10000 \mathrm{U}$ and SiLAC $0.1 \mathrm{U}$

manually kept the $\mathrm{pH} 8$ along the whole biotransformation to assure and steady $\omega$-HA production rate during the entire reaction course (Fig. 2). Controlling the $\mathrm{pH}$, the cell-free biocascade attained $90 \%$ yield of $\mathbf{2 d}$ after $24 \mathrm{~h}$ and using $100 \mathrm{mM}$ substrate without detecting none of the intermediates.

\section{Green and sustainablity metrics}

We assessed the sustainability of our cell-free multi-enzyme system and compared it with other reported methodologies where different catalysts as metal-based ${ }^{[23]}$ and resting whole-cells ${ }^{[7 b]}$ were employed for the synthesis of $\mathbf{2 d}$ (Fig. 3A).

We calculated mass-based green metrics ${ }^{[2]}$ of these three processes. In one hand the reaction mass efficiency (RME) and mass productivity (MP) were calculated as the mass of product

A

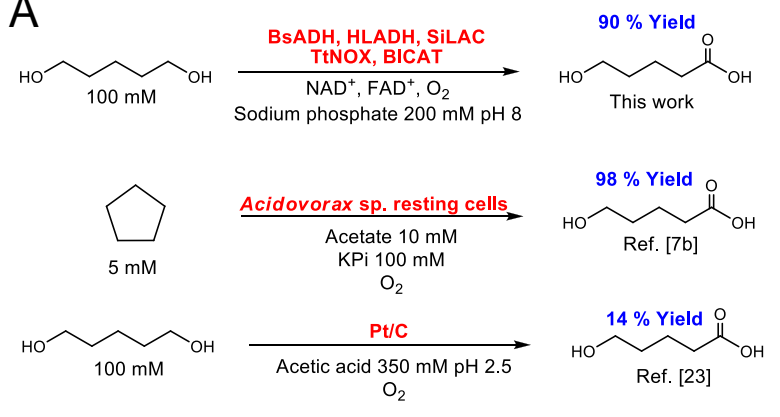

B
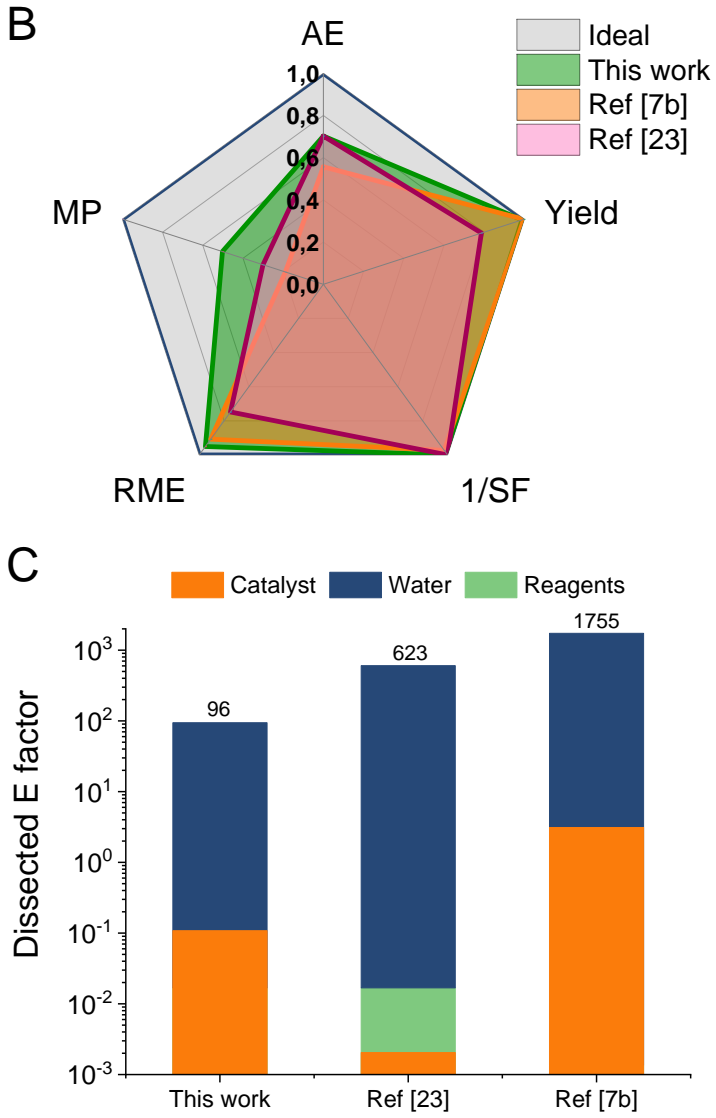

Figure 3. Different catalytic approaches for the synthesis of 2d. A) Comparative table with substrate, biocatalysts (red), conditions and product yield (blue). B) Green metrics for the synthesis of $\mathbf{2 d}$. $A E=$ atom economy. MP = mass productivity. RME: Reaction mass efficiency. $1 / \mathrm{SF}=$ the inverse of the stoichometry factor (SF). For more details, see experimental section C). Dissected E factor. 
divided by total mass of reactants only, and the total mass including catalysts and solvents, respectively. On the other hand, we also calculated the atom economy $(\mathrm{AE})$ and the stoichiometric factor (SF) for the three compared systems (Fig. 3B). Our system is the closest to an ideal one, where the weakest parameter is the MR mainly attributed to the large water excess employed for these transformations. Finally, we also calculate the $E$ factor of each process and the specific contribution of water, catalysts and reagents to that value in the three systems above mentioned. Our process presents 6.5 to 18.3 lower $E$ factor than the other methodologies herein compared, indicating that our cell-free system is more sustainable than the traditional metal catalyst and even with whole cells herein compared for the synthesis of $\mathbf{2} \mathbf{d}$ (Fig $3 C)$. However, water is also largely influencing the $E$ factor of the three transformations contributing in more than $96 \%$ of the total value of each catalytic approach.

\section{Immobilization of the cell-free multi-enzyme system}

To further intensify the process, we immobilized the five enzymes integrated in our cascade to enable the recycling of the biocatalytic system. Harnessing the His-tag fused to the $\mathrm{N}$ terminus of both BsADH and SiLAC (HB1), we co-immobilized these two enzymes on cobalt-activated agarose microbeads (AG$\mathrm{Co}^{2+}$ ) through metal coordination. This immobilized system was dubbed as heterogeneous biocatalysts 1 (HB1). Unfortunately, we could not co-immobilize the five-enzyme system on $\mathrm{AG}-\mathrm{Co}^{2+}$, since HLADH, TtNOX and BICAT lack the His-tag that drives the immobilization. For this reason, we covalently co-immobilized the untagged $\mathrm{HLADH}^{[25]}$, TtNOX ${ }^{[26]}$ and $\mathrm{BICA}^{[27]}$ on glyoxyl-activated agarose microbeads (AG-G) under alkaline conditions followed by mild reduction of the enzyme-carrier bonds; we named this system as heterogeneous biocatalyst 2 (HB2). This immobilization chemistry is driven by the reaction of the supportaldehyde groups with the free amino-residues of the surface lysines in the enzyme surface. Although the co-immobilization of HLADH, TtNOX and BICAT was never intended on AG-G, we selected this carrier because these three enzymes have been stabilized individually on AG-G. ${ }^{[25,28]}$ When both His-BsADH and His-SiLAC were immobilized on AG-G, these enzymes were fully inactivated upon the immobilization process. For this reason, we discarded AG-G as consensus carrier for the co-immobilization of the 5 enzymes and thus we were forced to use a consortium of heterogeneous biocatalysts (HB1 and HB2). Table 2 shows the immobilization parameters for HB1 and HB2, where all enzymes were immobilized in high yields (immobilization yields > $98 \%$ )

Table 2. Immobilization parameters of co-immobilized multienzyme systems.

\begin{tabular}{ccccc} 
Biocatalyst & Enzymes & $\begin{array}{c}\text { Immobilization } \\
\text { carrier }\end{array}$ & $\begin{array}{c}\Psi \\
(\%)^{a}\end{array}$ & $\begin{array}{c}\text { Recovered } \\
\text { activity } \\
(\mathrm{U} / \mathrm{g} \\
\text { support) } \\
(\%)\end{array}$ \\
\hline HB1 & BsADH & AG-Co $^{\text {b }}$ & 53 & $2.60(112)$ \\
& SiLAC & AG-G & 100 & $0.65(100)$ \\
\hline HB2 & HLADH & TtNOX & Ag & $0.35(81)$ \\
& BICAT & & 100 & $0.71(16)$ \\
\hline
\end{tabular}

${ }^{a}$ Immobilization yield, $\Psi=$ (immobilized activity/offered activity) $\mathrm{x} 100 .{ }^{\mathrm{b}}$ Recovered activity of the immobilized enzyme per gram of carrier after the immobilization process. ${ }^{c}(\%)$ is defined as the coefficient between the specific activity of the immobilized enzymes and the specific activity of the soluble ones.

except His-BsADH which only reached $53 \%$. In HB1, both BsADH and SiLAC recovered roughly $100 \%$ of their soluble specific activity upon the immobilization, whereas $\mathrm{HLADH}, \mathrm{TtNOX}$ and BICAT recovered $81 \%, 16 \%$ and $48 \%$, respectively when assembled as HB2. As TtNOX is an oxygen dependent flavin oxidase, its low recovered activity upon the immobilization on porous AG-G relies on oxygen diffusion limitation through the carrier microstructure. ${ }^{[23,26]}$

Once HB1 and HB2 were prepared, we mixed them to carry out the cell-free biosynthesis of $\mathbf{2} \mathbf{d}$ under batch operation conditions. Like the soluble multi-enzyme system, the immobilized one also accumulated the lactol $(\mathbf{2 b})$ but not the lactone $(\mathbf{2 c})$ during the first $5-8 \mathrm{~h}$ of reaction as the diol 2a was oxidized (Figure 4A). After 24 $\mathrm{h}$ of reaction, the immobilized multi-enzyme system yielded $62 \%$ of the $\omega-\mathrm{HA}$, a $33 \%$ lower $\omega-\mathrm{HA}$ yield than the one attained with the soluble enzymes. We suggest that the lower recovered activity of the immobilized enzymes (mainly the TtNOX that limit the cofactor recycling) were responsible for the less efficient performance of the heterogeneous biocatalysts. After one $24 \mathrm{~h}$ cycle, the two HBs were filtered and readily reutilized for two consecutives $24 \mathrm{~h}$ cycles.
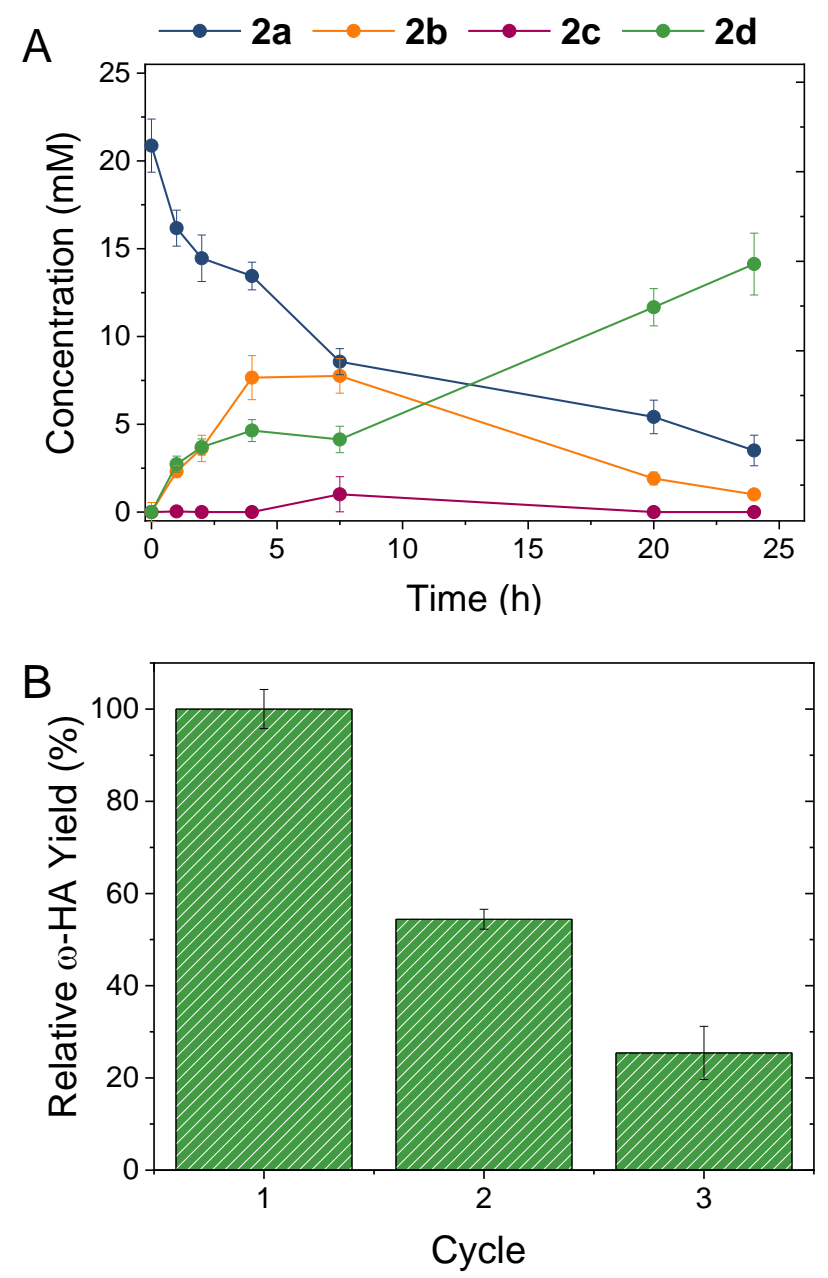

Figure 4. Cell-free synthesis of $\omega$-HAs catalyzed by heterogeneous biocatalysts. A) Reaction time-course of the first reaction cycle. B) Reutilization of $\mathrm{HB} 1$ and HB2 mixture in repeated batch reactions. After each reaction cycle the HBs mixture was filtered and washed two times with $0.5 \mathrm{~mL}$ of sodium phosphate buffer $25 \mathrm{mM} \mathrm{pH}$ 8. All reactions consisted in $1 \mathrm{~mL}$ of $20 \mathrm{mM}$ 2a, 1 $\mathrm{mM} \mathrm{NAD}^{+}, 0.15 \mathrm{mM} \mathrm{FAD}^{+}$in $100 \mathrm{mM}$ buffer $\mathrm{pH} 8$ at $30{ }^{\circ} \mathrm{C}$ and $250 \mathrm{rpm}$, containing $300 \mathrm{mg} \mathrm{HB} 1$ and $100 \mathrm{mg} \mathrm{HB}$. Each cycle corresponds to $24 \mathrm{~h}$ at the specified reaction conditions. 
Figure $4 \mathrm{~B}$ shows how the $\omega$-HA yield decreased $40 \%$ and $75 \%$ after the second and third cycles, respectively. The low conversion after the third operational cycle was mainly attributed to the inactivation of both ADHs which lost $98 \%$ of their initial activity (Supporting Information, Table S3). Therefore, our future efforts will focus on enhancing the operational stability of the immobilized ADHs under these specific reaction conditions.

\section{Conclusion}

In summary, we have developed an orchestrated multi-enzyme system that sequentially catalyzes the double oxidation of diols into lactones and their hydrolysis to ultimately yield $\omega-\mathrm{HA}$, integrating an efficient $\mathrm{NAD}^{+}$regeneration system that uses oxygen as ultimate electron acceptor. High $\omega$-HA yields were achieved through the synergistic combination of two ADHs possessing different catalytic efficiencies towards the diol and lactol oxidation, respectively. Furthermore, this multi-enzyme system was proven to transform a wide scope of linear and branched short-chain diols into their corresponding $\omega$-HAs, demonstrating an excellent enantioselectivity for the desymmetrization of prochiral diols such as 3-methyl-1,5pentanediol. Finally, we intensified this cell-free biotransformation by increasing the substrate concentration up to $100 \mathrm{mM}$ and immobilizing the multi-enzyme system to recycle a consortium of heterogeneous biocatalysts (involving the 5 enzymes immobilized on two different carriers) in consecutive operational cycles. In our study, oxygent mass transport was not intensified, however we envision oxygen bubling as efficient approach to enhance the $\mathrm{NAD}^{+}$recycling by boosting NOX activity that will ultimately accelerate the overall casacde rate, yielding higher $\omega$-HA titers in shorter times.

Thorough exploiting synergies in biocatalytic cascade reactions, this new artificial multi-enzyme cascade opens new paths to upgrade diols into molecules with higher industrial value. Our future efforts are directed at enhancing the overall stability of the multi-enzyme system and controlling its spatial distribution across the carrier surface to ultimately enhance the productivity and robustness of this multi-functional heterogenous biocatalytic system.

\section{Experimental Section}

\section{Materials and equipment}

Enzymes as alcohol dehydrogenase equine (HLADH) recombinant expressed in E. coli $0.5 \mathrm{U} / \mathrm{mg}$, catalase from bovine liver (BICAT) lyophilized powder $\sim 2000-5000 \mathrm{U} / \mathrm{mg}$ of protein and Horseradish peroxidase (HRP) 150 U/mg; substrates $1-7 a$, reaction products $1 \mathrm{~d}, \mathbf{4 d}$, $\mathbf{5 d}$, reagents as flavin-adenine-dinucleotide sodium salt $\left(F A D^{+}\right)$, sodium phosphate dibasic dihydrate, ABTS, $p$-nitrophenol, were acquired from Sigma-Aldrich (St. Louis, IL). Nicotinamide-adenine-dinucleotide sodium salt $\left(\mathrm{NAD}^{+}\right)$was purchased from GERBU Biotechnik $\mathrm{GmbH}$ (Wieblingen, Germany). Lactones 2c and 7c, $\omega$-HAs 7d, 5-oxopentanoic acid (2e) and 6-oxohexanoic acid (3e) were obtained from Enamine building blocks (Riga, Latvia). $\omega$-HAs 2d and 3d were purchased from Cymit (Barcelona, Spain). 6BCL agarose beads activated with glyoxyl groups (AG-G) was prepared as described elsewhere. ${ }^{[30]}$ Cobalt-activated agarose microbeads 4BCL $\left(\mathrm{AG}^{-\mathrm{Co}^{2+}}\right.$ ) (particle size; 50-150 $\mu \mathrm{m}$, pore size; $112 \mathrm{~nm}$ (mean value) and $15 \mu \mathrm{mol}$ of $\mathrm{Co}^{2+} \times$ gcarrier $^{-1}$ ) were purchased from $\mathrm{ABT}$ technologies (Madrid, Spain). Precision plus protein ${ }^{\mathrm{TM}}$ standards, micro Bio-spin ${ }^{\mathrm{TM}}$ chromatographic columns and Bradford reagent were acquired from BIORAD. All other reagents and solvents were analytical grade or superior.

\section{Enzyme production and purification}

Alcohol dehydrogenase from Bacillus stearothermophilus (BsADH), lactonases from Sulfolobus islandicus (SiLAC), from Rhodococcus erythropolis (ReLAC), NADH oxidase from Thermus thermophilus (TtNOX) were overexpressed in Escherichia coli BL21 cells, whereas alcohol oxidase from Phanerochaete chrysosporium F101S variant $\left(\mathrm{PcAOX}^{*}\right)$ was overexpressed in ArticExpress (DE3) E. coli cells.

Expression: A total of $1 \mathrm{~mL}$ of an overnight culture of $E$. coli transformed with the respective plasmids (pET28b-bsadh-BsADH, or pET28b-silac, or pET28b-relac, or pET28b-repon1lac, or pET22-ttnox, or pET28b-pcaoxf101s) was inoculated in a $50 \mathrm{~mL}$ of Luria-Bertani (LB) broth containing kanamycin (final concentration of $30 \mu \mathrm{g} \mathrm{mL}^{-1}$ ) for BsADH, SiLAC, ReLAC and ampicillin $\left(100 \mu \mathrm{g} \mathrm{mL}^{-1}\right)$ for TtNOX or a mixture of kanamycin and gentamycin (30 and $20 \mu \mathrm{g} \mathrm{mL}^{-1}$, respectively) for PcAOX-F101S. The culture was incubated at $37^{\circ} \mathrm{C}$ (in the case of BsADH, SiLAC, ReLAC, RePON1LAC and TtNOX) or $30{ }^{\circ} \mathrm{C}$ (in the case of PcAOX-F101S) at 250 rpm until the $\mathrm{OD}_{600 \mathrm{~nm}}$ reached 0.6. At that point, the culture was induced with $1 \mathrm{mM}$ of 1 -thio- $\beta$-d-galactorpyranoside (IPTG) in the case of BsADH, TtNOX and PcAOX-F101S, whereas for SiLAC, ReLAC and RePON1LAC the induction IPTG concentrations were $1 \mu \mathrm{M}, 1 \mathrm{mM}$ and $1 \mu \mathrm{M}$, respectively. Cells were grown at $37^{\circ} \mathrm{C}$ for $3 \mathrm{~h}$ (in the case of BsADH and TtNOX) or at $21{ }^{\circ} \mathrm{C}$ for $24 \mathrm{~h}$ (in the case of SiLAC, ReLAC and RePON1LAC) or at $13^{\circ} \mathrm{C}$ for $24 \mathrm{~h}$ (in the case of PCAOX-F101S) and then harvested by centrifugation at $1290 \mathrm{~g}$ during $30 \mathrm{~min}$ at $4 \stackrel{\circ}{\circ}$.

Purification. All recombinatly expressed enzymes but TtNOX were purified by affinity as follows: the resulting pellet was resuspended in one-tenth of its original volume of $25 \mathrm{mM}$ sodium phosphate buffer solution $(\mathrm{pH}=7)$ for BsADH, SiLAC, ReLAC and RePON1LAC and $50 \mathrm{mM}$ sodium phosphate buffer $\mathrm{pH} 7.8$ supplemented with $0.150 \mathrm{M} \mathrm{NaCl}, 0.1 \mathrm{M} \mathrm{KCl}, 20 \mathrm{mM}$ imidazole, $0.1 \mathrm{mM} \mathrm{FAD}{ }^{+}$for PcAOX-F101S. Cells were broken by sonication at an amplitude of $40 \%$ with alernating cycles of $3 \mathrm{~s}$ on $/ 5 \mathrm{~s}$ off during 20 min at $4{ }^{\circ} \mathrm{C}$ (Sonopuls HD 4100, Bandelin). The cell lysate was centrifuged at $10528 \mathrm{~g}$ during $30 \mathrm{~min}$ at $4 \stackrel{\circ}{\circ} \mathrm{C}$. The supernatant containing the enzyme was collected and passed through a cobalt-activated agarose resin equilibrated with binding buffer. The column was incubated for $1 \mathrm{~h}$ at $4 \stackrel{\circ}{ } \mathrm{C}$ to promote the protein binding to the column. Afterwards the column was washed three times with binding buffer prior to the protein elution with elution buffer (binding buffer supplemented with $300 \mathrm{mM}$ imidazole). The eluted protein was gel-filtered by using PD-10 columns (GE healthcare) to remove the imidazole and exchange the enzyme buffer to $10 \mathrm{mM}$ sodium phosphate $\mathrm{pH}$ 7. TtNOX was purified as follows: the cells were resuspended in one-tenth of its original volume of $10 \mathrm{mM}$ sodium phosphate buffer solution $\mathrm{pH} 7$ and broken by sonication (Sonopuls HD 4100 , Bandelin) at amplitude $=40 \%$ alernating cycles of $3 \mathrm{~s}$ on $/ 5 \mathrm{~s}$ off during $20 \mathrm{~min}$ at $4 \stackrel{\circ}{\circ}$. The suspension was centrifuged at $10528 \mathrm{~g}$ during $30 \mathrm{~min}$ at $4 \stackrel{\circ}{\circ}$. The supernatant containing the enzyme was incubated at $70 \stackrel{\circ}{\circ} \mathrm{C}$ for $1 \mathrm{~h}$ to remove all mesophilic proteins, the thermophilic one remain at the supernatant that is separated by centrifugation at $10528 \mathrm{~g}$ during 30 $\min$ at $4 \stackrel{\circ}{\circ}$. The supernatant was pased through a polyethyleneimineactivated agarose (AG-PEI) where this enzyme is not attached. ${ }^{[26]}$ SDSPAGE and Bradford assays were carried out after each production batch to determine the purity, concentration and specific activity of the enzymes (Supporting Information, Fig. S2).

In the case of the commercial preparation of HLADH, we determined the enzyme concentration with a calibration curve of BSA in a SDS-PAGE gel (Supporting Information, Fig. S1). According to this calibration curve, the 
HLADH commercial extract has $0.37 \pm 0.014 \mathrm{mg}$ of enzyme / $\mathrm{mg}$ of crude powder.

\section{Enzyme activity measurements}

Enzyme activities were spectrophotometrically measured in transparent 96-well microplates, employing a Microplate Reader Epoch 2, BioTek® with the software Gen5.

\section{ADH activity}

$200 \mu \mathrm{L}$ of a reaction mixture containing the substrate (diols or lactol) and the cofactor $\mathrm{NAD}^{+}$(at the specified concentrations) in sodium phosphate buffer at $\mathrm{pH} 8$ were incubated with $5 \mu \mathrm{L}$ of enzymatic solution or suspension (properly diluted) at $30^{\circ} \mathrm{C}$. The increase in the absorbance at $340 \mathrm{~nm}$ due to the NADH formation was recorded. One unit of activity was defined as the amount of enzyme that was required to reduce $1 \mu \mathrm{mol}$ of $\mathrm{NAD}^{+}$to $\mathrm{NADH}$ per minute at the assayed conditions.

\section{Alcohol oxidase activity}

$200 \mu \mathrm{L}$ of a reaction mixture containing the substrate $(2 \mathrm{a}$, at the specified concentration), HRP $10 \mu \mathrm{g} / \mathrm{mL}$, ABTS $1 \mathrm{mg} / \mathrm{mL}$ in sodium phosphate buffer at $\mathrm{pH} 8$ were incubated with $5 \mu \mathrm{L}$ of enzymatic solution or suspension (properly diluted) at $30^{\circ} \mathrm{C}$. The increase in the absorbance at $414 \mathrm{~nm}$ due to the ABTS oxidation triggered by the $\mathrm{H}_{2} \mathrm{O}_{2}$ formed by the oxidase, was recorded. One unit of activity was defined as the amount of enzyme that was required to produce $1 \mu \mathrm{mol}$ hydrogen peroxide per minute at the assayed conditions.

\section{Lactonase activity}

Lactonase activity was indirectly monitored by the decrease in the $\mathrm{pH}$ triggered by the $\omega$-HA formation from its corresponding lactone hydrolysis. Briefly, $200 \mu \mathrm{L}$ of a reaction mixture containing the $1 \mathrm{mM}$ of $\delta$ valerolactone, $0.1 \%$ acetonitrile, $0.25 \mathrm{mM}$ p-nitrophenol in $2.5 \mathrm{mM}$ sodium phosphate buffer at pH 7.0 were incubated with $5 \mu \mathrm{L}$ of enzymatic solution or suspension (properly diluted) at $30^{\circ} \mathrm{C}$. The decrease in the absorbance of $p$-nitrophenol ( $\mathrm{pH}$ indicator) at $410 \mathrm{~nm}$ was recorded. One unit of activity was defined as the amount of enzyme that was required to produce $1 \mu \mathrm{mol}$ $\omega$-hydroxy acid per minute at the assayed conditions.

\section{Catalase activity}

The activity was determined by recording the decrease in the absorbance at $240 \mathrm{~nm}$ of $200 \mathrm{~mL}$ of a reaction mixture containing $35 \mathrm{mM}$ hydrogen peroxide in $100 \mathrm{mM}$ sodium phosphate $\mathrm{pH} 8$ at $30{ }^{\circ} \mathrm{C}$. The reaction was initiated by adding $5 \mu \mathrm{L}$ of the enzymatic solution or suspension to the reaction mixture. One unit of CAT activity was defined as the amount of enzyme required for the disproportionation of one $\mu \mathrm{mol}$ of hydrogen peroxide per minute at the assessed conditions.

\section{NADH oxidase activity}

$200 \mu \mathrm{L}$ of a reaction mixture containing $0.2 \mathrm{mM} \mathrm{NADH}$ and $150 \mu \mathrm{M} \mathrm{FAD}{ }^{+}$ in $50 \mathrm{mM}$ sodium phosphate buffer $\mathrm{pH} 8$ at $30 \stackrel{\circ}{\circ} \mathrm{C}$ were incubated with 5 $\mu \mathrm{L}$ of enzymatic solution or suspension (properly diluted) at $30{ }^{\circ} \mathrm{C}$. The decrease in the absorbance at $340 \mathrm{~nm}$ was monitored. One unit of activity was defined as the amount of enzyme that was required to oxidize $1 \mu \mathrm{mol}$ of NADH per minute at the assayed conditions.

\section{Synthesis of $\omega-H A$}

Either soluble or immobilized enzymes were placed inside a capped plastic tube ( 2 or $5 \mathrm{~mL}$ ) containing a reaction mixture $(0.5$ or $1.5 \mathrm{~mL}$, as indicated) consisted in either 20 or $100 \mathrm{mM}$ of substrate (1a, 2a, 3a, $\mathbf{4 a}, \mathbf{5 a}, \mathbf{6 a}$ or 7a), $1 \mathrm{mM} \mathrm{NAD}^{+}, 0.15 \mathrm{mM} \mathrm{FAD}^{+}$in $200 \mathrm{mM}$ sodium phosphate buffer $\mathrm{pH}$ 8. The cap of the tube was punched with an open needle to allow atmospheric oxygen supplementation. Reactions were incubated at $30^{\circ} \mathrm{C}$ at $250 \mathrm{rpm}$ inside an orbital incubator. When specified, $\mathrm{pH}$ was manually adjusted by the addition of $\mathrm{NaOH} 1 \mathrm{M}$. Reaction course was monitoring by withdrawing samples at periodic intervals which were analyzed by chromatographic methods (Supporting Information, Table S4). The concentration of substrate, intermediates and products were determined by GC analysis at different time points. Particularly, the lactone and $\omega-\mathrm{HA}$ concentration were calculated with a double analysis as described in Supporting Information, Scheme S1. We estimated the 6d yield qualitatively by NMR analysis calculating the ratio between the integration values of the doublets relative to $\mathrm{CH}_{3}$ of $6 \mathbf{d}(3.00)$ at $0.90 \mathrm{ppm}$ and $\mathrm{CH}_{3}$ of the unknown product (1.13) that lies between 0.95-1.00 ppm (Supporting Information, Fig. S15).

\section{Chromatographic methods}

\section{Gas Chromatography (GC)}

Prior GC analysis reaction samples were derivatized as described elsewhere. ${ }^{[31]}$ During sample derivatization, lactones are hydrolyzed to their corresponding $\omega$-HAs, therefore before sample derivatization, lactones must be removed by liquid-liquid extraction with ethyl acetate as follows: $100 \mu \mathrm{L}$ of aqueous reaction sample were mixed with $400 \mu \mathrm{L}$ of ethyl acetate and vortexed for $20 \mathrm{~s}$ and centrifuged $1 \mathrm{~min}$ at $1000 \mathrm{~g}$. After extraction, the organic phase was stored for further GC analysis and the aqueous phase was further derivatized. The lactone was determined in the organic phase, while the $\omega$-HA was quantified in the aqueous phase. We analyzed every reaction sample both with and without lactone extraction. Diols and lactols were quantified by direct sample derivatization without lactone extraction. Samples were derivatized by placing $30 \mu \mathrm{L}$ of the aqueous reaction simple in a $1.5 \mathrm{~mL}$ Eppendorf tube, followed by the addition of $30 \mu \mathrm{L}$ of $N$-methylimidazole and $225 \mu \mathrm{L}$ of acetic anhydride and incubated by $10 \mathrm{~min}$ at room temperature. Afterwards, $300 \mu \mathrm{L}$ of distilled water was added and allowed to cool down. Later, liquid-liquid extraction of acetylated compounds was done by the addition of $300 \mu \mathrm{L}$ of dichloromethane containing $2 \mathrm{mM}$ eicosane as internal standard discarding the aqueous phase. $30-50 \mathrm{mg}$ of anhydrous $\mathrm{MgSO}_{4}$ were added to dry samples before $\mathrm{GC}$ analysis. Gas chromatography analyses were carried out in an Agilent $8890 \mathrm{GC}$ system chromatograph using a J\&W HP$5 \mathrm{GC}$ column $(30 \mathrm{~m} \times 0.32 \mathrm{~mm} \times 0.25 \mu \mathrm{m})$, helium as carrier gas, and equipped with a flame ionization detector (FID). Injector at $280^{\circ} \mathrm{C}, \mathrm{FID}$ at $300 \stackrel{\circ}{\circ}$. Separation of acetylated derivatives and extracted compounds in ethyl acetate were done by the following temperature program: initial temperature at $60{ }^{\circ} \mathrm{C}$, maintained $2 \mathrm{~min}$, ramp to $160 \stackrel{\circ}{\circ} \mathrm{C}$ at a rate of 10 ${ }^{\circ} \mathrm{C} / \mathrm{min}$, ramp 2 to $240{ }^{\circ} \mathrm{C}$ at a rate of $20{ }^{\circ} \mathrm{C} / \mathrm{min}$ and finally maintained 4 min. Retention times are listed in Supporting Information, Table S4. The samples were additionally analyzed using a Agilent 7820A Series Gas Chromatograph a J\&W HP-5 GC column $(30 \mathrm{~m} \times 0.25 \mathrm{~mm} \times 0.25 \mu \mathrm{m})$, coupled to an Agilent $5975 \mathrm{C}$ inert XL Mass Spectrometer with Electronic Impact ionization

\section{Chiral GC chromatography}

Prior chiral GC analysis, reaction samples were treated with ethyl acetate to remove residual lactones as aforementioned. Once lactones were removed aqueous samples were derivatized to obtain acetylated $\omega-\mathrm{HA}$ as previously described. Once acetylated, samples were analyzed in an Agilent 8890 GC system chromatograph using a chiral column (Supporting Information, Table S5), helium as carrier gas, and equipped with a flame ionization detector (FID). Injector at $280{ }^{\circ} \mathrm{C}$, FID at $280{ }^{\circ} \mathrm{C}$. Separation of acetylated derivatives were done under chromatographic conditions described in Supporting Information, Table S5.

\section{High Performance Liquid Chromatography (HPLC) analysis}

Prior HPLC analysis reaction samples were derivatized as described elsewhere. ${ }^{[32]}$ Briefly, $10 \mu \mathrm{L}$ of aqueous sample $(0.6-20 \mathrm{mM})$ were mixed with $50 \mu \mathrm{L}$ of O-benzylhydroxylamine hydrochloride $(130 \mathrm{mM}$ in pyridine:methanol:water $33: 15: 2)$ and incubated for $5 \mathrm{~min}$ at $25 \stackrel{\circ}{\circ} \mathrm{C}$ 
Afterwards, $500 \mu \mathrm{L}$ of methanol were added and then centrifuged $5 \mathrm{~min}$ at 13450 g. HPLC analysis was conducted in an Agilent Technologies 1260 Infinity chromatograph equipped with a Poroshell EC-C18 column $(4.6 \mathrm{x}$ $100 \mathrm{~mm}, 2.7 \mu \mathrm{m}$ ). Samples were detected at $215 \mathrm{~nm}$ and were eluted at 1 $\mathrm{mL} / \mathrm{min}$ flow rate employing two mobile phases; phase $A$ composed by trifluoroacetic acid $0.1 \%$ in water, and phase $\mathrm{B}$ composed by trifluoroacetic acid $0.095 \%$ in $4: 1$ acetonitrile:water. Elution conditions: $10 \%$ to $100 \%$ of B over 30 min. Retention times of O-benzylhydroxylamine derivatives were: 5-oxopentanoic acid (2e): $14.7 \mathrm{~min}$, and 6-oxohexanoic acid (3e): $16.3 \mathrm{~min}$.

\section{Nuclear Magnetic Resonance (NMR) analysis}

When specified, reaction samples were analyzed by ${ }^{1} \mathrm{H}$ NMR spectra acquired on a Bruker $500 \mathrm{MHz}$ Ultra Shield spectrometer, operating at 500 $\mathrm{MHz}$ for ${ }^{1} \mathrm{H}-\mathrm{NMR}$. Chemical shifts were reported in parts-per-million $(\delta$, $\mathrm{ppm}$ ) and referenced using the residual solvent peak (deuterium oxide $\delta=$ $4.79 \mathrm{ppm})$. Coupling constants $(\mathrm{J})$ were reported in hertz $(\mathrm{Hz})$. The multiplicity of the signals were reported as singlet (s), doublet (d), doublet of doublets of doublets of doublets (dddd), doublet of quartet (dq), doublet of triplet (dt), triplet (t) and multiplet $(\mathrm{m})$.

\section{Green metrics}

The sustainability of this work was obtained by calculating the green metrics of the present cell-free multi-enzyme system applied in the synthesis of $\mathbf{2 d}$, compared with other reported approaches. To this aim, we employed the following equations:[24, 33]

Product mass: Product obtained after one cycle (g).

Waste mass: Is the product mass subtracted from the total mass in the bulk accounting for the reagents, the solvent (including water) and the catalyst.

Waste mass $=($ Total reagents mass $(g)+$ total water mass $(g)+$ total catalyst mass $(g))-$ Product mass $(g)$

E factor $=$ Waste mass $/$ Product mass

$\boldsymbol{A} \boldsymbol{E}=\Sigma M W$ products $/ \Sigma M W$ reagents

SF (mass stoichiometry factor or excess reactant factor): this parameter means the excess of reagents regarding the limiting reagent. In this study. For those reaction using $\mathrm{O}_{2}$, we consider it in stoichiometric amounts as their supply to the reaction crude will be constant although its dissolved concentration will not be higher than $200 \mu \mathrm{M}$ under the stirring conditions used in our reaction set-up ${ }^{[29]}$.

$S F=1+(\Sigma$ mass excess reagents $(g) / \Sigma$ ) Eq. 4

The stoichiometric mass is calculated as the coefficient between the mass of $\mathbf{2} \mathbf{a}$ divided by the mass of $\mathbf{2} \mathbf{d}$.

Yield $=$ Yield of reaction $(\%)$

$\boldsymbol{R M E}=$ Mass of product $(g) /$ Total mass of reactants $(g)$

$\boldsymbol{M P}=$ Mass of product $(g) / T$

The dissected $\mathbf{E}$ factor, was obtained by division of the mas of each contributor by the mass of the products according with the following equations:

$$
\begin{array}{lr}
\text { Efactor }_{\text {reagents }}={ }^{\text {Total reagents mass }(g) / \text { Product mass }(g)} & \text { Eq. } 8 \\
\text { Efactor }_{\text {water }}={ }^{\text {Total water mass }(g) / \text { Product mass }(g)} & \text { Eq. } 9 \\
{\text { f } \text { factor }_{\text {catalyst }}=}^{\text {Total catalyst mass }(g) / \text { Product mass }(g)} & \text { Eq. } 10
\end{array}
$$

\section{Enzyme co-immobilization}

Enzyme co-immobilization on $\mathrm{AG}^{-\mathrm{Co}^{2+}}$ microbeads: heterogeneous biocatalyst 1 (HB1)

The enzymes were immobilized by mixing 10 volumes of purified BsADH and crude cell extract of SiLAC (His-tagged proteins) with 1 volume of AG$\mathrm{Co}^{2+}$ microbeads and incubated under orbital shaking for $1 \mathrm{~h}$ at $4 \stackrel{\circ}{\circ} \mathrm{C}$. Later, the suspension was filtered and the microbeads containing the enzymes were washed with 5 volumes of $25 \mathrm{mM}$ phosphate buffer at $\mathrm{pH}$ 7. The immobilized biocatalyst (HB1) was stored at $4{ }^{\circ} \mathrm{C}$.

Co-immobilization on AG-G microbeads: heterogeneous biocatalyst 2 (HB2)

10 volumes of $\mathrm{HLADH}$ in $100 \mathrm{mM}$ bicarbonate buffer $\mathrm{pH} 10$ were added to 1 volume of AG-G. The suspension was incubated at $25^{\circ} \mathrm{C}$ under orbital agitation for $30 \mathrm{~min}$. Afterwards, the suspension was filtered and the AG$G$ microbeads containing the immobilized HLADH were mixed with 10 volumes of an enzyme mixture of TtNOX and BICAT in $100 \mathrm{mM}$ bicarbonate buffer $\mathrm{pH} 10$. Likewise, the suspension was incubated at $4 \stackrel{\circ}{\circ} \mathrm{C}$ under orbital agitation for $3 \mathrm{~h}$. Subsequently, a reduction step was achieved by the addition of $1 \mathrm{mg} / \mathrm{mL}$ of sodium borohydride and maintained under agitation at $4^{\circ} \mathrm{C}$ for $30 \mathrm{~min}$. After the reduction step, the immobilised preparation (HB2) was fully washed with $10 \mathrm{mM}$ phosphate buffer $\mathrm{pH} 7$, filtered and stored at $4^{\circ} \mathrm{C}$.

\section{Acknowledgements}

We all want to acknowledge the funds from IKERBASQUE, EraCoBiotech (Project ID: 61 HOMBIOCAT), ERC-CoG-2018 (Project ID: 818089 METACELL), and Spanish State Research Agency (AIE) (RTI 2018-094398-B-I00, PCI 2018-092984). This work was supported by the Spanish Ministry of Science and Innovation under the Maria de Maeztu Units of Excellence Programme (MDM - 2017 - 0720).

Supporting information for this article is available on the WWW.

\section{Declaration of interest}

The authors declare no competing financial interest.

Keywords: $\omega$-hydroxy acid synthesis • multi-enzyme systems • dehydrogenase $\cdot$ lactonase

[1] aA. Köckritz, A. Martin, Eur. J. Lipid Sci. Technol. 2011, 113, 83-91; bF Zhang, C. Huang, T. Xu, Ind. Eng. Chem. Res. 2009, 48, 7482-7488.

[2] D. Puppi, F. Chiellini, Appl. Mater. Today 2020, 20, 100700.

[3] C. L. Soliday, P. E. Kolattukudy, Plant Physiol. 1977, 59, 1116-1121.

[4] Y. luchi, M. Hyotanishi, B. E. Miller, K. Maeda, Y. Obora, Y. Ishii, J. Org Chem. 2010, 75, 1803-1806.

[5] aS. Cheong, J. M. Clomburg, R. Gonzalez, Nat. Biotechnol. 2016, 34, 556-561; bC. H. Martin, H. Dhamankar, H.-C. Tseng, M. J. Sheppard, C R. Reisch, K. L. J. Prather, Nat. Commun. 2013, 4, 1414; cS. Lim, H.-w. Yoo, S. Sarak, B.-g. Kim, H. Yun, J. Ind. Eng. Chem. 2021, 98, 358-365; dT.-H. Kim, S.-H. Kang, J.-E. Han, E.-J. Seo, E.-Y. Jeon, G.-E. Choi, J.B. Park, D.-K. Oh, ACS Catal. 2020, 10, 4871-4878; eJ. Ge, X. Yang, H. Yu, L. Ye, Metab. Eng. 2020, 62, 172-185.

[6] S.-H. Pyo, J. H. Park, V. Srebny, R. Hatti-Kaul, Green Chem. 2020, 22, 4450-4455. 
[7] aF. Wang, J. Zhao, Q. Li, J. Yang, R. Li, J. Min, X. Yu, G.-W. Zheng, H.L. Yu, C. Zhai, C. G. Acevedo-Rocha, L. Ma, A. Li, Nat. Commun. 2020, 11, 5035; bD. Salamanca, K. Bühler, K.-H. Engesser, A. Schmid, R. Karande, New Biotechnol. 2021, 60, 200-206.

[8] A. Pennec, F. Hollmann, M. S. Smit, D. J. Opperman, ChemCatChem 2015, 7, 236-239.

[9] J. W. Song, E. Y. Jeon, D. H. Song, H. Y. Jang, U. T. Bornscheuer, D. K. Oh, J. B. Park, Angew. Chem. Int. Ed. Engl. 2013, 52, 2534-2537.

[10] S. Watanabe, F. Fukumori, H. Nishiwaki, Y. Sakurai, K. Tajima, Y. Watanabe, Sci. Rep. 2019, 9, 155.

[11] C. J. B. van der Vlugt-Bergmans, M. J. van der Werf, Appl. Environ. Microbiol. 2001, 67, 733-741.

[12] H. Mallin, H. Wulf, U. T. Bornscheuer, Enzyme Microb. Technol. 2013 , 53, 283-287.

[13] A. Pellis, S. Cantone, C. Ebert, L. Gardossi, New Biotechnol. 2018, 40, 154-169.

[14] aS. Kara, D. Spickermann, J. H. Schrittwieser, A. Weckbecker, C. Leggewie, I. W. C. E. Arends, F. Hollmann, ACS Catal. 2013, 3, 24362439; bA. Díaz-Rodríguez, J. Iglesias-Fernández, C. Rovira, V. GotorFernández, ChemCatChem 2014, 6, 977-980; cC. D. Dithugoe, J. van Marwijk, M. S. Smit, D. J. Opperman, ChemBioChem 2019, 20, 96-102.

[15] aA. Bornadel, R. Hatti-Kaul, F. Hollmann, S. Kara, ChemCatChem 2015, 7, 2442-2445; bR. Zuhse, C. Leggewie, F. Hollmann, S. Kara, Org. Process. Res. Dev. 2015, 19, 369-372.

[16] A. Díaz-Rodríguez, I. Lavandera, S. Kanbak-Aksu, R. A. Sheldon, V. Gotor, V. Gotor-Fernández, Advanced Synthesis \& Catalysis 2012, 354 3405-3408.

[17] C. Martin, M. Trajkovic, M. W. Fraaije, Angew. Chem. Int. Ed. 2020, 59, 4869-4872.

[18] aA. Burgard, M. J. Burk, R. Osterhout, S. Van Dien, H. Yim, Curr. Opin. Biotech. 2016, 42, 118-125; bY. Jiang, W. Liu, H. Zou, T. Cheng, N. Tian, M. Xian, Microb. Cell Fact. 2014, 13, 165.

[19] aS. Velasco-Lozano, J. Santiago-Arcos, J. A. Mayoral, F. López-Gallego, ChemCatChem 2020, 12, 3030-3041; bS. Velasco-Lozano, M. Roca, A Leal-Duaso, J. A. Mayoral, E. Pires, V. Moliner, F. López-Gallego, Chem Sci. J. 2020, 11, 12009-12020.

[20] J. Santiago-Arcos, S. Velasco-Lozano, E. Diamanti, A. L. Cortajarena, F. López-Gallego, Front. Chem. 2021, 1

[21] Q.-T. Nguyen, E. Romero, W. P. Dijkman, S. P. de Vasconcellos, C. Binda, A. Mattevi, M. W. Fraaije, Biochem. 2018, 57, 6209-6218.

[22] L. Kirmair, D. L. Seiler, A. Skerra, Appl. Microbiol. Biotechnol. 2015, 99 , 10501-10513

[23] M. S. Ide, R. J. Davis, J. Catal. 2013, 308, 50-59.

[24] R. A. Sheldon, ACS Sustain. Chem. Eng 2018, 6, 32-48.

[25] J. M. Bolivar, L. Wilson, S. A. Ferrarotti, J. M. Guisán, R. FernándezLafuente, C. Mateo, J. Biotechnol. 2006, 125, 85-94.

[26] J. Rocha-Martín, D. Vega, J. M. Bolivar, C. A. Godoy, A. Hidalgo, J. Berenguer, J. M. Guisán, F. López-Gallego, BMC Biotechnol. 2011, 11, 101.

[27] L. Betancor, A. Hidalgo, G. Fernández-Lorente, C. Mateo, R. FernándezLafuente, J. M. Guisan, Biotechnol. Prog. 2003, 19, 763-767.

[28] S. Velasco-Lozano, J. Rocha-Martin, E. Favela-Torres, J. Calvo, J. Berenguer, J. M. Guisán, F. López-Gallego, Biochem. Eng. J. 2016, 112, 136-142.

[29] A. I. Benítez-Mateos, C. Huber, B. Nidetzky, J. M. Bolivar, F. LópezGallego, ACS Appl. Mater. Interfaces 2020, 12, 56027-56038.

[30] C. Mateo, J. M. Palomo, M. Fuentes, L. Betancor, V. Grazu, F. LópezGallego, B. C. C. Pessela, A. Hidalgo, G. Fernández-Lorente, R. Fernández-Lafuente, J. M. Guisán, Enzyme Microb. Technol. 2006, 39 274-280.

[31] J. Wu, M.-H. Li, J.-P. Lin, D.-Z. Wei, J. Chromatogr. Sci. 2011, 49, 375378.

[32] K. Hernandez, J. Bujons, J. Joglar, S. J. Charnock, P. Domínguez de María, W. D. Fessner, P. Clapés, ACS Catal. 2017, 7, 1707-1711.

[33] J. Andraos, in Green Chemistry Metrics, 2008, pp. 69-199. 
